\title{
Prevalence of hypogammaglobulinemia and its management with subcutaneous immunoglobulin supplementation in patients after allogeneic hematopoietic stem cell transplantation-a single-center analysis
}

\author{
Ewa Karakulska-Prystupiuk ${ }^{1}$ • . Jadwiga Dwilewicz-Trojaczek ${ }^{1}$. Joanna Drozd-Sokołowska' ${ }^{1}$ Ewelina Kmin ${ }^{2}$. \\ Marcin Chlebus ${ }^{3} \cdot$ Karolina Szczypińska $^{1} \cdot$ Piotr Boguradzki $^{1} \cdot$ Agnieszka Tomaszewska $^{1} \cdot$ Krzysztof Mądry $^{1}$. \\ Jarosław Biliński ${ }^{1}$. Grzegorz Władysław Basak ${ }^{1}$. Wiesław Wiktor Jędrzejczak ${ }^{1}$
}

Received: 21 March 2021 / Accepted: 18 August 2021 / Published online: 3 September 2021

(c) The Author(s) 2021

\begin{abstract}
Secondary immunodeficiencies are frequently observed after allo-HSCT. The efficacy of subcutaneous IgG preparations in this population is unknown. A retrospective single-institution study involved 126 adult patients transplanted in 2012-2019 for hematological malignancies. Patients were tested every 2-3 weeks for plasma IgG concentration during the 1 st year after transplantation and supplemented with facilitated subcutaneous immunoglobulin when they either had IgG concentration $<500 \mathrm{mg} / \mathrm{dl}$ or between 500 and $700 \mathrm{mg} / \mathrm{dl}$ and recurrent infection. The $\mathrm{IgG}$ concentration $<500 \mathrm{mg} / \mathrm{dL}$ was diagnosed in 41 patients, while $500-700 \mathrm{mg} / \mathrm{dL}$ in 25 and altogether 53 patients received $\mathrm{IgG}$ supplementation. The median number of IgG administrations was 2. The median time to the first IgG administration after allo-HSCT was 4.1 months, while to the next administration (if more than one was required) 53 days (prophylactic group) and 32 days (group with infections). We did not observe any significant toxicity. Two situations were associated with increased probability of meeting criteria for IgG supplementation: diagnosis of either acute lymphoblastic leukemia (ALL) or chronic lymphocytic leukemia (CLL) (83.8\% versus $39.3 \%$ for other diagnosis, $p=0.000)$ and the systemic use of corticosteroids $(64.2 \%$ versus $31.5 \%$ for patients without systemic corticosteroids, $p=0.005$ ). Over $40 \%$ of the adult recipients may require at least incidental immunoglobulin supplementation during the first year after allo-HSCT. Low IgG concentrations are associated with inferior outcomes. The subcutaneous route of IgG administration appeared to be safe and may allow for long persistence.
\end{abstract}

Keywords Immunoglobulin G (IgG) · Secondary immunodeficiencies (SIDs) · Allogeneic Hematopoietic stem cell transplantation (allo-HSCT) $\cdot$ Subcutaneous immunoglobulins $\cdot$ Hypogammaglobulinemia

\section{Introduction}

Despite a considerable reduction in the incidence of nonrelapse mortality following allogeneic hematopoietic stem cells transplantation (allo-HSCT) in recent years, infectionrelated mortality remains a challenge in the post-transplantation care $[1,2]$. It is related to secondary immunodeficiencies that are frequently observed and are multifactorial in etiology [3-6]. According to NCCN (National Comprehensive Cancer Network) guidelines, allo-HSCT recipients

Ewa Karakulska-Prystupiuk

ewa.prystupiuk@uckwum.pl

Extended author information available on the last page of the article (with neutrophil recovery) who require intensive immunosuppressive therapy for graft-versus-host disease (GHVD) are an example of non-neutropenic patients at great risk for infections [7]. Humoral immunodeficiencies may result in a quantitative, qualitative, and functional shortage of immunoglobulins [3-6].

However, EMA guideline on the clinical investigation of human normal immunoglobulin for intravenous administration [8] does not specify post allo-HSCT care and broadly discusses secondary immunodeficiencies to use proven failure to produce specific antibody among others as an indication for their use. Allo-HSCT recipients during the first year after transplantation fall into this category [7]. 
Immunoglobulin supplementation is commonly used in allo-HSCT recipients to prevent and treat infections, but also to modulate acute GvHD. However, there is an ongoing controversy about the benefit of such therapy, dosing regimens, and treatment monitoring of the immunoglobulin supplementation [7-12]. Additionally, immunoglobulin concentrates for subcutaneous administration are being more frequently administered instead of intravenous preparations, and to our best knowledge, there is no report on this subject in the available literature. Therefore, we find it important to report our experience with subcutaneous immunoglobulins.

\section{Material and methods}

\section{Study population}

Patients treated at the Outpatient Transplantation Service, transplanted in the years 2012-2019 were included. Patients who died shortly after allo-HSCT, and had not been referred to the Outpatient Service, were not included.

\section{Allo-HSCT}

Conditioning was chosen on the discretion of treating physician and depended on the underlying hematological disease. Immunosuppressive treatment was combined of calcineurin inhibitor (cyclosporin or tacrolimus) and antiproliferative drug-either short course of methotrexate or mycophenolate mofetil. All patients with unrelated or mismatched donors received anti-T cell globulin $(2,5-5 \mathrm{mg} / \mathrm{kg}$ daily) for 2-3 days in conditioning regimen. Immunosuppressive therapy was discontinued after 6-8 months following alloHSCT if GVHD did not occur. Diagnosis and grading of acute and chronic GVHD were performed based on clinical symptoms and/or biopsies according to established criteria [6]. Grading of acute GvHD was performed according to Glucksberg score, while the severity of chronic GvHDaccording to National Institutes of Health (NIH) Consensus Criteria 2014 [13-15]. All patients received anti-infective prophylaxis and vaccinations according to the NIH guidelines $[9,16]$ including prophylactic bacterial treatment with oral phenoxymethylpenicillin (1500 units twice daily) or oral levofloxacin (500-1000 mg twice daily), as described in the Supplement.

\section{Doses and types of immunoglobulin, the indications for supplementation therapy}

All patients were systematically tested (once every 2-3 weeks) and immunoglobulin concentration was determined. Serum $\operatorname{IgG}$ was analyzed by the immunoturbidimetric method (Roche biochemical analyzer Cobas 8000, reagent Tina-quant IgG Gen.2) at the Central Laboratory of the Medical University of Warsaw (reference normal level: $700-1600 \mathrm{mg} / \mathrm{L}$ ).

The patients received immunoglobulin supplementation based on the CDC (Centers for Disease Control and Prevention) recommendation and the NIH guidelines $[6,9]$. Due to the difficulty in obtaining intravenous preparations, subcutaneous preparations were mostly used. Since the vast majority of patients had transient immunoglobulin deficiencies, IgG was administered solely if the pre-administration IgG concentration was beyond the predefined threshold.

The doses and frequencies of immunoglobulin supplementation were given according to the individual patients' requirements. Patients with $\mathrm{IgG}$ level below $500 \mathrm{mg} / \mathrm{dL}$ were classified as significantly deficient and received prophylactic immunoglobulins at a dose of $0.4-0.8 \mathrm{~g} / \mathrm{kg}$. Patients with episodes of severe infection within the first 12 months after transplantation who had $\mathrm{IgG}$ level below $700 \mathrm{mg} / \mathrm{dL}$ received IgG supplementation at a dose of $0.5-1.0 \mathrm{~g} / \mathrm{kg}$ (divided into 2 doses). Preparations used were as follows: immunoglobulin facilitated subcutaneously by recombinant human hyaluronidase (10\% infusion) - HyQvia (Baxalta Innovations $\mathrm{GmbH}$, Austria) or/and solution $165 \mathrm{mg} / \mathrm{mL}-\mathrm{Gam}$ manorm (Octapharma, UK). The patients who had received intravenous IgG (IVIg) at the beginning of the study were switched to subcutaneous preparations of immunoglobulin (after at least 28 days of the last IVIg dose). Subcutaneous preparations were always administered under the abdominal skin using a variable rate portable pump according to the producer instructions. Immunoglobulin administration was preceded by hyaluronidase administration in case of HyQvia.

Adverse events were graded according to CTCAE (Common Terminology Criteria for Adverse Events v5.0) [17].

\section{Statistical analysis}

This is a retrospective analysis. Medians, means, and standard deviations were calculated for continuous and ordered variables. In the search of predictors that increase the need for IgG supplementation, the logistic regression model was used. The following variables were tested: gender, diagnosis being an indication for transplantation, type of conditioning, type of donor, GvHD occurrence (acute and chronic GVHD were considered only if they were documented prior to the landmark of the first IgG supplementation), age of the recipient on the day of allo-HSCT, age of the recipient at the time of diagnosis, use of corticosteroids before the first IgG supplementation. Likelihood ratio test was calculated and presented along with standard error. If not mentioned otherwise, the level of statistical significance was set up at $5 \%$. The analyses were conducted using $\mathrm{R}$ version 3.6.1. All time-to-event endpoints were computed from the day of allo-HSCT. The Kaplan-Meier estimator and log-rank test 
were used for overall survival. For the multiple comparisons, after Bonferroni adjustment for 6 comparisons between the 4 different clinical groups (A-no IgG supplementation group, B-prophylactic IgG group, C-IgG $<500 \mathrm{mg} / \mathrm{dL}$ and infection, D-IgG 500-700 $\mathrm{mg} / \mathrm{dL}$ and infection), it was necessary to recalculate $\mathrm{p}[0.05 / 6$ (6 comparisons $)=0.008]$ and $p<0.008$ corresponded to the same overall level of significance.

\section{Results}

\section{Patients}

One hundred twenty-six patients, 74(58\%) males, with median age at allo-HSCT 46 years (range 18-71) were included into the analysis. For twelve patients, it was the second allo-HSCT. The most prevalent diagnoses were acute leukemia, both myeloid (AML)-54\%, and lymphoblastic (ALL)-13.5\%. Baseline patients' characteristics are shown in Table 1.

\section{Transplantations}

HLA-identical siblings were used for $38(30.2 \%)$ patients, matched unrelated donors for 66(52.4\%), mismatched unrelated donors for $19(15.1 \%)$, and haploidentical related donors for $3(2.4 \%)$. There were $86(68,2 \%)$ patients, who received myeloablative conditioning (MAC), 35(27.8\%) reduced-intensity conditioning (RIC), and 5(4\%) non-myeloablative conditioning (NMA).

\section{Treatment after transplantation}

Thirty-four patients (27\%) received additional therapy after transplantation (mainly azacitidine) aimed at preventing relapse. The detailed information on this treatment is provided in the Supplement.

\section{Immunosuppressive therapy}

All patients received prophylactic anti-GvHD treatment, including 84 patients (67\%)-cyclosporine $\mathrm{A}(\mathrm{CsA})$ and $28(22 \%)$-tacrolimus (TAC), together with short course of methotrexate. There were 4 patients who received posttransplant cyclophosphamide (PT-Cy) after haploidentical
Table 1 Baseline patients' characteristics ( $A A$ aplastic anemia, $A M L$ acute myeloid leukemia, $A L L$ acute lymphoblastic leukemia, $G V H D$ graft versus host disease, $M A C$ myeloablative conditioning, $M D S$ myelodysplastic syndrome, $M P N$ myeloproliferative neoplasm, $M M U D$ mismatched unrelated donor, $M R D$ matched related donor, $M U D$ matched unrelated donor, NMA non-myeloablative conditioning, $R I C$ reduced intensity conditioning)

\begin{tabular}{|c|c|c|}
\hline & Number of patients & $\begin{array}{l}\text { Share of } \\
\text { the total } \\
(\%)\end{array}$ \\
\hline \multicolumn{3}{|l|}{ Gender } \\
\hline Male & 74 & 59 \\
\hline Female & 52 & 41 \\
\hline \multicolumn{3}{|l|}{ Age in years } \\
\hline $18-40$ & 49 & 39 \\
\hline $40-60$ & 55 & 44 \\
\hline$>=60$ & 22 & 17 \\
\hline \multicolumn{3}{|l|}{ Diagnosis } \\
\hline AML & 68 & 54 \\
\hline MDS & 13 & 10 \\
\hline ALL & 17 & 14 \\
\hline AA & 6 & 5 \\
\hline MPN & 9 & 7 \\
\hline Lymphoma & 13 & 10 \\
\hline \multicolumn{3}{|l|}{ Conditioning } \\
\hline MAC & 86 & 68 \\
\hline NMA & 5 & 4 \\
\hline RIC & 35 & 28 \\
\hline \multicolumn{3}{|l|}{ Donor } \\
\hline MRD & 37 & 30 \\
\hline MUD & 66 & 52 \\
\hline MMUD & 19 & 15 \\
\hline haplo & 4 & 3 \\
\hline \multicolumn{3}{|l|}{ Acute GvHD } \\
\hline Grade $1-2$ & 28 & 22 \\
\hline Grade $3-4$ & 11 & 9 \\
\hline \multicolumn{3}{|l|}{ Chronic GvHD } \\
\hline Mild & 13 & 10 \\
\hline Moderate & 46 & 37 \\
\hline Severe & 22 & 17 \\
\hline
\end{tabular}

HSCT. Other protocols included: CsA or TAC combined with mycophenolate mofetil (MMF) (4 patients(3\%)) or TAC with sirolimus (6 patients(5\%)). Three patients received either MMF (2 patients(2\%)) or sirolimus (1 patient $(1 \%)$ ).

\section{GvHD}

Acute graft-versus-host disease (aGvHD) was diagnosed in 39 patients $(30.9 \%)$ including $28(22.2 \%)$ with grade $1-2$, and $11(8.7 \%)$ with grade $3-4$. Chronic graft-versushost disease (cGvHD) was diagnosed in 81 patients $(64 \%)$, 
including 13(10\%) with mild, 46(37\%)-moderate, and 22(17\%)-severe cGvHD.

\section{Prevalence of IgG deficiencies after allo-HSCT}

Hypogammaglobulinemia below $500 \mathrm{mg} / \mathrm{dL}$ detected at least once occurred in $32.5 \%$ of patients (41 out of 126). In most patients, hypogammaglobulinemia was occasional and transient, and only in $10.3 \%$ of patients (13 out of 126 ), it was chronic. Additionally, in 25 patients IgG level below $700 \mathrm{mg} / \mathrm{dL}$ but above $500 \mathrm{mg} / \mathrm{dL}$ was observed making the total number of IgG deficient patients 66 out of 126(52.4\%). $47 \%$ of patients did not have a decreased IgG level and about $4 \%$ of them had hypergammaglobulinemia. Eight patients developed monoclonal gammopathy. The lowest IgG level that has served as an indication for IgG supplementation in all analyzed patients are summarized in Table 2.

Altogether 53 out of 126 patients (42\%) received IgG supplementation with exogenous immunoglobulin. Immunoglobulin facilitated subcutaneously by recombinant human hyaluronidase was used in $85 \%$ cases and solution $165 \mathrm{mg} /$ $\mathrm{mL}-$ in $15 \%$ cases.

IgG was administered to all patients in whom $\operatorname{IgG}$ level was below $500 \mathrm{mg} / \mathrm{dL}$ (41 patients (32.5\%)). In 25 of them, it was only prophylactic, while in the remaining 16 also therapeutic because of recurrent infections. Additionally, 12 patients with $\mathrm{IgG}$ in the range $500-700 \mathrm{mg} / \mathrm{dL}$ with accompanying severe and recurrent infections also received $\operatorname{IgG}$ supplementation. Therefore, the entire group of patients with infection receiving IgG supplementation comprised 28 patients ( 16 with $\operatorname{IgG}$ below $500 \mathrm{mg} / \mathrm{dL}$ and 12 with $\operatorname{IgG}$ in the range $500-700 \mathrm{mg} / \mathrm{dL}$ ). The median number of $\operatorname{IgG}$ administrations was 3.5 (range 1-8) in the prophylactic, and 2 (range 1-8) in the group with infection.

The occurrence of the following invasive or life-threatening infections was used as an indication for IgG administration: fungal pneumonia-7 patients (25\%), bacterial pneumonia-2(7\%), sepsis within preceding months-15(53\%), recurrent local infection-7(24\%), viral infection-25(89\%) (including BK virus infection of the urinary tract10(35.7\%), CMV reactivation-10 (35.7\%)), and polymicrobial infections-13 patients(46\%).

Beside $\mathrm{IgG}$ supplementation, they received appropriate routine antimycotic, antibacterial or/and antiviral treatment. Patients with BK virus infection did not receive any antiviral treatment.

The median time to the first $\operatorname{IgG}$ administration was 4.1 months (range 1.1-74.2) after allo-HSCT, and 13 months after diagnosis (for the entire group) (range 4.1-173.9).

Median IgG levels before IgG therapy initiation were $460 \mathrm{mg} / \mathrm{dL}$ (range 190-480) in the prophylaxis group, $446 \mathrm{mg} / \mathrm{dL}$ (range 200-494) in patients with IgG level below $500 \mathrm{mg} / \mathrm{dL}$, and recurrent infections and $557 \mathrm{mg} / \mathrm{dL}$ (range 519-670) in the group of patients with infections and IgG level below 700 but above $500 \mathrm{mg} / \mathrm{dL}$.

Thirteen of $126(10.3 \%)$ patients ( 3 out of 3 with chronic lymphocytic leukemia (CLL), 1 out of 4 with Hodgkin lymphoma (HL), 6 out of 68 with AML and 3 out of 17 with ALL) required regular IgG supplementation throughout the follow-up period with median 8 administrations per year (range 8-9).

While it is a retrospective and not a prospective study aiming at assessing regular pharmacokinetics, patients were controlled for IgG concentration at various time points after IgG subcutaneous administration. Nevertheless, subcutaneous $\mathrm{IgG}$ significantly increased $\mathrm{IgG}$ concentration that was maintained for 6-8 weeks. Patients originally suffering from ALL (82\%) and lymphoma (58\%) most frequently met the criteria for IgG supplementation and were accordingly treated. The characteristics of patients treated with IgG are shown in Table 3.

\section{Survival analysis}

The 1-year overall survival (1-y OS) was 97.1\%(95\% CI, 89.1-99.3) in the group that never required immunoglobulin supplementation, 95.8\%(95\% CI, 73.9-99.4) in the prophylactic IgG group, $80.6 \%$ (95\% CI, 51-93.3) in the group with
Table 2 The lowest IgG level that has served as an indication for IgG supplementation in all analyzed patients

\begin{tabular}{llllll}
\hline IgG $(\mathrm{mg} / \mathrm{dL})$ & $\begin{array}{l}\text { Number of patients } \\
\text { (Share of the total) }\end{array}$ & $\begin{array}{l}\text { Prophylactic IgG } \\
\text { (Share of the total) }\end{array}$ & $\begin{array}{l}\text { Therapeutic IgG } \\
\text { (Share of the } \\
\text { total) }\end{array}$ & $\begin{array}{l}\text { Relapse } \\
\text { (Share of the } \\
\text { total) }\end{array}$ & $\begin{array}{l}\text { Death } \\
\text { (Share of } \\
\text { the total) }\end{array}$ \\
\hline$<200$ & $1(0,1 \%)$ & $1(0,1 \%)$ & 0 & 0 & 0 \\
$200-300$ & $8(6.3 \%)$ & $4(3.1 \%)$ & $4(3.1 \%)$ & $1(0.1 \%)$ & $1(0.1 \%)$ \\
$300-400$ & $13(10.3 \%)$ & $10(7.9 \%)$ & $3(2.4 \%)$ & $3(2.4 \%)$ & $3(2.4 \%)$ \\
$400-500$ & $19(15 \%)$ & $10(7.9 \%)$ & $9(7 \%)$ & $4(3.1 \%)$ & $5(4.4 \%)$ \\
$500-700$ & $25(20 \%)$ & 0 & $12(9.4 \%)$ & $3(2.4 \%)$ & $4(3.1 \%)$ \\
$700-1600$ & $55(44 \%)$ & 0 & 0 & $6(4.9 \%)$ & $6(4.9 \%)$ \\
$>1600$ & $5(4.3 \%)$ & 0 & 0 & $1(0.1 \%)$ & $1(0.1 \%)$ \\
Total & $126(100 \%)$ & $25(19 \%)$ & $28(22 \%)$ & $18(13 \%)$ & $20(15 \%)$ \\
\hline
\end{tabular}


Table 3 Characteristics of patients treated with IgG

\begin{tabular}{|c|c|c|}
\hline & $\begin{array}{l}\text { Patients requiring } \mathrm{IgG} / \mathrm{All} \\
\text { patients } N=53 / 126\end{array}$ & $\begin{array}{l}\text { The pro- } \\
\text { portion in } \\
\text { total }\end{array}$ \\
\hline \multicolumn{3}{|l|}{ Sex } \\
\hline M & $37 / 74$ & $50 \%$ \\
\hline $\mathrm{F}$ & $16 / 52$ & $30 \%$ \\
\hline \multicolumn{3}{|l|}{ Diagnosis } \\
\hline AML & $20 / 68$ & $29 \%$ \\
\hline MDS & $6 / 13$ & $46 \%$ \\
\hline ALL & $14 / 17$ & $82 \%$ \\
\hline AA & $2 / 6$ & $33 \%$ \\
\hline MPN & $4 / 9$ & $44 \%$ \\
\hline Lymphoma & $7 / 12$ & $58 \%$ \\
\hline (including CLL) & $(3 / 3)$ & $(100 \%)$ \\
\hline \multicolumn{3}{|l|}{ Dono } \\
\hline haplo & $2 / 4$ & $50 \%$ \\
\hline MMUD & $11 / 19$ & $57 \%$ \\
\hline MRD & $17 / 37$ & $46 \%$ \\
\hline MUD & $23 / 66$ & $35 \%$ \\
\hline \multicolumn{3}{|l|}{ Conditioning } \\
\hline MAC & $38 / 86$ & $44 \%$ \\
\hline NMA & $2 / 5$ & $40 \%$ \\
\hline RIC & $13 / 35$ & $37 \%$ \\
\hline \multicolumn{3}{|l|}{ GvHD } \\
\hline AcuteGvHD & $27 / 39$ & $69 \%$ \\
\hline ChronicGvHD & $46 / 81$ & $56 \%$ \\
\hline
\end{tabular}

recurrent infections treated with $\operatorname{IgG}$ because of $\mathrm{IgG}$ level below $500 \mathrm{mg} / \mathrm{dL}$, and finally $63.5 \%(95 \% \mathrm{CI}, 28.9-84.7)$ in the group treated with IgG because of recurrent infections and IgG 500-700 mg/dL. Relapse was the primary cause of death in 7 out of 7 patients, 4 out of 5 patients, 4 out of 4 patients and 3 out of 4 patients respectively.

The 1-y OS differences for four clinical groups (A-no IgG supplementation group, B-prophylactic IgG group, $\mathrm{C}-\mathrm{IgG}<500 \mathrm{mg} / \mathrm{dL}$ and infection, D-IgG 500-700 mg/ dL, and infection) A vs. B, A vs. C, A vs. D, B vs. C, B vs. $\mathrm{D}, \mathrm{C}$ vs. D were not statistically significant. The survival curves for all groups using Kaplan-Meier estimator are presented in Fig. 1. Detailed results of the statistically significant 1-y OS differences are shown in Table S4 (supplement).

Despite the fact that relapse contributed to death of $90 \%$ of all deceased patients, various infections complicated the course of relapse (mainly pneumonia or sepsis). Nine out of 10 patients $(90 \%)$ with BKV infection receiving IgG improved, and thus achieved successful control of hemorrhagic cystitis, while 1 patient died (10\%) due to relapse of the underlying disease. Detailed causes of death and diagnosed infections that occurred during the last 14 days of patients' lives are presented in Table S5 (supplement).

\section{Factors predictive for IgG supportive treatment}

In the logistic regression model, the diagnosis of ALL or CLL and the use of systemic corticosteroid therapy were associated with the need for IgG supplementation. The average probability that a patient diagnosed with ALL or CLL will require IgG supplementation was $83.8 \%$, while for patients with other diagnoses the average probability was $39.3 \%(p=0.0001)$. The use of corticosteroids was associated with the average probability of hypogammaglobulinemia requiring IgG supplementation in $64.2 \%$, while no corticosteroid use with $31.5 \%(p=0.005)$ only.

\section{Toxicity}

Adverse events were observed in 53\% patients treated with fscIgG, including 49\%-grade 1 and $4 \%$-grade 2 . In two male patients $(5 \%)$ transient scrotal edema was observed, which resolved without any medical intervention. Malaise was reported in 2 patients (4\%) and discomfort at the injection site in 10 patients $(22 \%)$ patients. In 6 patients $(13 \%)$ who suffered from chronic kidney disease-a clinically insignificant transient decrease in creatinine clearance was observed. In 3 patients (6\%) of all treated patients, the change of the type of $\mathrm{IgG}$ products was required due to an allergic skin reaction at the application site.

\section{Discussion}

Apart from relapse of the underlying malignancy and graft versus host disease, secondary immunodeficiency is the most common complication of allo-HSCT. All patients are affected to some degree. It results in the occurrence of infectious complications, but also in an increased risk of relapse by altered effectiveness of graft-versus-leukemia reaction $[3-6,18]$. The occurrence of immunodeficiency, due to the altered and insufficient recovery of the immune system, is influenced by many factors including pre-transplant, like patient's age, type of the underlying medical condition and its treatment (including a growing number of therapeutics targeting B cells), peri-transplant factors related to the transplantation procedure, e.g. the type of the donor, type of conditioning, ATG use and post-transplant factors i.e. multi-stage course of reconstitution, complications especially GvHD, immunosuppressive treatment and preventive treatment used after transplantation [18-22].

While this immunodeficiency is complex involving various parts and mechanisms of the immune system with limited possibility for intervention, the deficiency of immunoglobulins, particularly IgG can be corrected with exogenous 
Fig. 1 Overall survival of patients with and without $\mathrm{IgG}$ supplementation

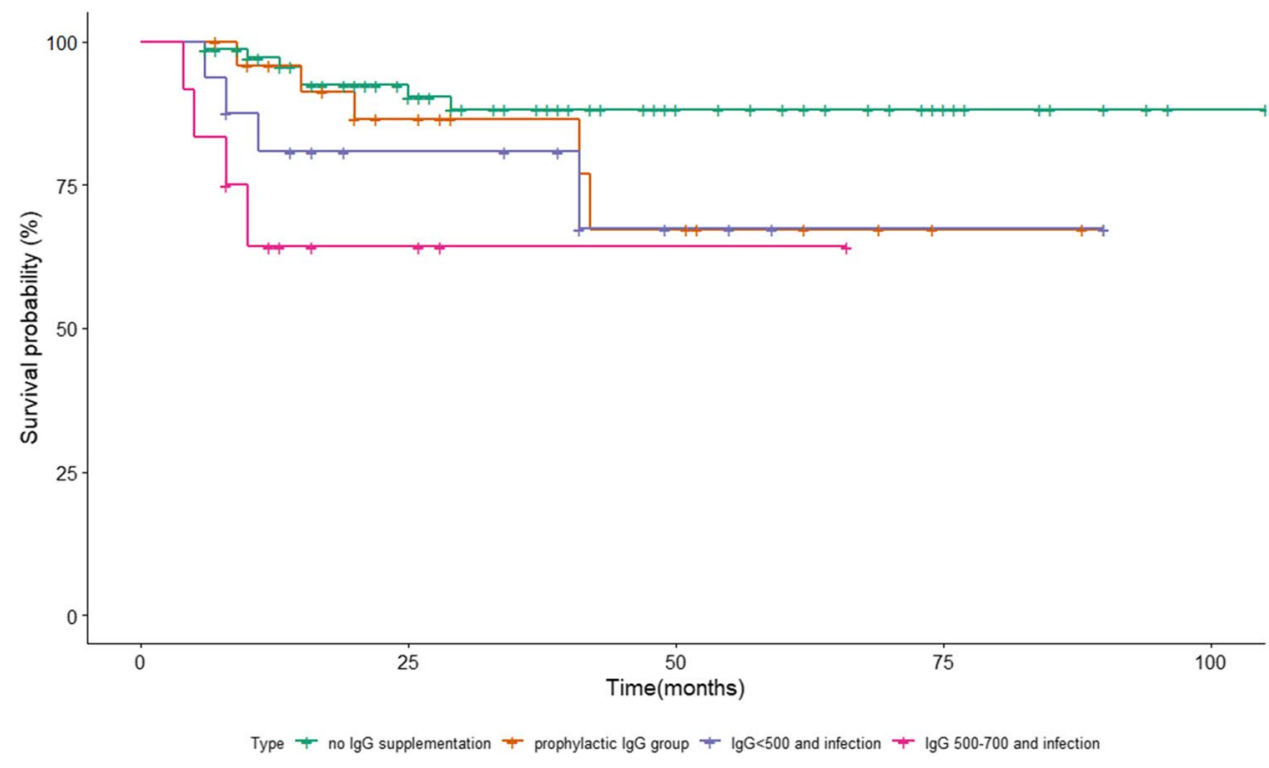

preparations. Nevertheless, expert opinions regarding IgG supplementation after allo-HSCT remain ambiguous [23-27].

In our group allo-HSCT recipients, IgG deficiency was usually transient and the supplementation of $\mathrm{IgG}$ was interventional in most cases. Approximately $32 \%$ of recipients required incidental IgG supplementation while only $10 \%$ of them required regular supplementation every 3 weeks to maintain IgG level above $500 \mathrm{mg} / \mathrm{dl}$. Patients received immunoglobulins when they met the predefined criteria, i.e., when either the $\mathrm{IgG}$ level was below $500 \mathrm{mg} / \mathrm{dL}$, or below $700 \mathrm{mg} / \mathrm{dL}$ (but above $500 \mathrm{mg} / \mathrm{dL}$ ) with frequent infections or both.

The IgG level used in this study as the indication for preventive $\operatorname{IgG}$ supplementation was higher than the one $(<400 \mathrm{mg} / \mathrm{dL}$ ) recommended by the ASBMT (American Society for Blood and Marrow Transplantation) and EBMT (The European Society for Blood and Marrow Transplantation) guidelines $[6,9]$. The reason for this modification was the use of subcutaneous preparation of $\mathrm{IgG}$, which efficacy in this population of patients was unknown.

Given possible qualitative and functional shortages of immunoglobulins, we used IgG replacement as part of supportive care, for patients with higher IgG concentration who suffered with infections. The effectiveness of $\mathrm{IgG}$ is difficult to assess reliably because, usually, we administered causal treatment at the same time as the $\mathrm{IgG}$ replacement. It is worth noting that $90 \%$ of supplemented patients, suffering from symptomatic BK Polyomavirus- associated hemorrhagic cystitis in grade II or III (according to the ECIL-6 Guidelines) [28, 29] achieved the resolution of symptoms without any antiviral treatment.

The median time to the first $\operatorname{IgG}$ administration (4.1 months) in our analysis appears to be consistent with the course of B-cell reconstitution, described in the literature $[4,5]$. Most of supplemented patients suffered from GvHD. Both acute and chronic GvHD are associated with delayed $\mathrm{B}$ cell reconstitution, reduction or lack of $\mathrm{B}$ cell precursors in the bone marrow and delays in $\mathrm{IgG} 2$ and $\mathrm{IgG} 4$ production $[5,30,31]$. Whether IgG supplementation may be useful to correct deficiencies of different IgG subclasses was beyond the scope of this study.

Cordonnier et al. reported an increased risk of fatal venoocclusive disease/sinusoidal obstruction syndrome (VOD/ SOS) in patients with acute GvHD receiving IgG replacement [32]. In our work, the shortest time to first administration was 34 days and we did not observe this complication.

Survival analysis revealed inferior survival in the group with infections than the prophylactic group but the vast majority of patients who eventually died, succumbed primarily to relapse of their leukemia with infection being only an accompanying condition. It needs further research to assess whether groups of patients with lower levels of $\mathrm{IgG}$ relapse more frequently than patients without $\mathrm{IgG}$ immunodeficiency.

In our study, the occurrence of IgG deficiency was found to be mainly dependent on the disease being an indication for transplantation, with ALL and CLL being the most common, and on systemic use of corticosteroid throughout the treatment process. In patients with B-cell malignancies total and/or functional hypogammaglobulinemia results from disease-related effects on the immune system and from side effects of the treatment [19, 26, 27]. Anti-B-cell therapy used before transplantation may be responsible for the development of post-transplantation complications. Low pre-allo-HSCT IgG level is a significant risk factor for hypogammaglobulinemia after transplantation [18-21]. 
In our study, no correlation for IgG replacement was found for GvHD (acute and/or chronic). The results of our analysis may be due to small number of analyzed patients, but also may indicate a stronger impact of steroid therapy than the diagnosis of GvHD on the occurrence of hypogammaglobulinemia. Corticosteroids are the current gold- standard for the treatment of GvHD [6]. According to published studies $[5,31]$ it is difficult to determine the causality of antibody deficiency following allo-HSCT in a situation where both GvHD and the corticosteroid therapy can lead to antibody deficiency. Greinix et al. described that impairment of reconstitution, observed in patients with GvHD (either acute or chronic) cannot be separated from the possible influence of corticosteroids [33].

To our best knowledge, this study is the first to describe the effectiveness and safety of subcutaneous preparations instead of intravenous. This treatment was well tolerated, and we did not observe any significant toxicity. According to the literature, IgG has a half-life of about 21 to 29 days following intravenous administration [34]. However, especially in patients with immunodeficiencies, interindividual variation has been reported. Taking into consideration variability of the patient's situation (different time after transplantation, different initial diagnosis, the severity of GVHD) and also the fact that they had endogenous IgG production (albeit reduced), these data have shown that subcutaneous IgG significantly increased IgG level that was maintained for 6-8 weeks.

While there was no systematic pharmacokinetic experiment, our data collected from patients more frequently tested may unexpectedly suggest that the half-life of subcutaneously administere $\operatorname{IgG}$ is longer than intravenously, at least in this setting, in which some endogenous IgG production is present [34-36]. This would require verification in a prospective study but is interesting and potentially useful. Promising results of the scIgG treatment may grant a possibility of at-home treatment for selected patients after allo-HSCT.

To conclude, over $40 \%$ of the adult stem cell recipients may require immunoglobulin supplementation. A vulnerable group of patients to the development of hypogammaglobulinemia after allo-HSCT are patients with B-cell neoplasms, such as acute lymphoblastic leukemia or chronic lymphocytic leukemia, as well as patients treated with corticosteroids after transplantation. Subcutaneous immunoglobulins replacement seems to be a safe and efficacious alternative to intravenous $\operatorname{IgG}$ preparations in patients after allo-HSCT.

Supplementary Information The online version contains supplementary material available at https://doi.org/10.1007/s00277-021-04649-y.
Acknowledgements This research did not receive any specific grant from funding agencies in the public, commercial, or not-for-profit sectors.

We thank all the patients, their families, and the members of staff involved in their care.

Author contribution All authors contributed to the study conception. The first draft of the manuscript was written by Ewa KarakulskaPrystupiuk and all authors commented on previous versions of the manuscript. All authors read and approved the final manuscript.

Conceptualization: Ewa Karakulska-Prystupiuk, Wiesław Wiktor Jędrzejczak.

Methodology: Ewa Karakulska-Prystupiuk, Wiesław Wiktor Jędrzejczak,

Formal analysis and investigation: Marcin Chlebus, Joanna Drozd-Sokołowska.

Writing_-original draft preparation: Ewa Karakulska-Prystupiuk, Jadwiga Dwilewicz-Trojaczek.

Writing-review and editing: Ewa Karakulska-Prystupiuk, Wiesław Wiktor Jędrzejczak, Joanna Drozd-Sokołowska, Jarosław Biliński.

Funding Resources: Karolina Szczypińska, Ewelina Kmin, Piotr Boguradzki, Agnieszka Tomaszewska, Krzysztof Mądry, Jarosław Biliński, Grzegorz Władysław Basak.

Supervision: Wiesław Wiktor Jędrzejczak, Grzegorz Władysław Basak.

Data availability All patient data was collected based on available medical records. All of the data was analyzed anonymously.

Code availability Not applicable.

\section{Declarations}

Ethics approval The ethical consent was approved by Medical University of Warsaw, Bioethical Commission.

Consent to participate This is a retrospective analysis of anonymous data contained in medical records.

Consent for publication Not applicable because there is no identifying information about patients.

Conflict of interest Author Wiesław Wiktor Jędrzejczak has received research support from: Roche, Novartis, Celgene, Janssen-Cilag, Takeda, Abbvie and BMS companies. Other authors declare no financial interests.

Open Access This article is licensed under a Creative Commons Attribution 4.0 International License, which permits use, sharing, adaptation, distribution and reproduction in any medium or format, as long as you give appropriate credit to the original author(s) and the source, provide a link to the Creative Commons licence, and indicate if changes were made. The images or other third party material in this article are included in the article's Creative Commons licence, unless indicated otherwise in a credit line to the material. If material is not included in the article's Creative Commons licence and your intended use is not permitted by statutory regulation or exceeds the permitted use, you will need to obtain permission directly from the copyright holder. To view a copy of this licence, visit http://creativecommons.org/licenses/by/4.0/. 


\section{References}

1. Passweg JR, Baldomero H, Chabannon C, Basak GW, Corbacioglu S, Duarte R, Dolstra H, Lenkester AC, Mohty M, Montoto S, de Latour RP, Snowden JA, Styczyński J, Yakoub-Agha I, Kröger N (2020) European Society for Blood and Marrow Transplantation (EBMT). The EBMT activity survey on hematopoietic-cell transplantation and cellular therapy 2018: CAR-T's come into focus. Bone Marrow Transplant 55(8):1604-1613. https://doi. org/10.1038/s41409-020-0826-4

2. Styczyński J, Tridello G, Koster L, Iacobelli S, van Biezen A, van der Werf S, Mikulska M, Gil L, Cordonnier C, Lyungman P, Averbuch D, de la Camara R, Baldomelo H, Bader P, Basak G, Bonini C, Duarte R, Dufour C, Kuball J, Lankester A, Montoto S, Nagler A, Snowden JA, Kröger N, Mohty M, Gratwohl A (2020) Infectious Diseases Working Party EBMT. Death after hematopoietic stem cell transplantation: changes over calendar year time, infections and associated factors. Bone Marrow Transplant 55(1):126-136. https://doi.org/10.1038/s41409-019-0624-z

3. Norlin AC, Sairafi D, Mattsson J, Ljungman P, Ringdén O, Remberger M (2008) Allogeneic stem cell transplantation: low immunoglobulin levels associated with decreased survival. Bone Marrow Transplant 41(3):267-273. https://doi.org/10.1038/sj.bmt. 1705892

4. Storek J (2008) Immunological reconstitution after hematopoietic cell transplantation - its relation to the contents of the graft. Expert OpinBiolTher 8(5):583-597. https://doi.org/10.1517/14712598.8. 5.583

5. Ogonek J, KraljJuric M, Ghimire S, Varanasi PR, Holler E, Greinix H, Weissinger E (2016) Immune Reconstitution after Allogeneic Hematopoietic Stem Cell Transplantation. Front Immunol 17(7):507. https://doi.org/10.3389/fimmu.2016.00507

6. Carreras E, Dufour C, Mohty M, Kroger N 2019 (eds), The EBMT Handbook, eBook, https://doi.org/10.1007/978-3-030-02278-5.

7. Baden LR, Bensinger W, Angarone M, Casper C, Dubberke ER, Freifeld AG, Garzon R, Greene JN, Greer JP, Ito JI, Karp JE, Kaul DR, King E, Mackler E, Marr KA, Montoya JG, Morris-Engemann A, Pappas PG, Rolston K, Segal B, Seo SK, Swaminathan S, Naganuma M, Shead DA (2012) National Comprehensive Cancer Network. Prevention and treatment of cancer-related infections. J NatlComprCancNetw 10(11):1412-45. https://doi.org/10.6004/ jnccn.2012.0146

8. European Medicines Agency, Guidelines on the clinical investigation of human normal immunoglobulin for intravenous administration. 28 June 2018. https://www.ema.europa.eu/en/documents/ scientific-guideline/guideline-clinical-investigation-human-normal-immunoglobuin-intravenous-administration-ivig-rev-3_en. pdf

9. Tomblyn M, Chiller T, Einsele H, Gress R, Sepkowitz K, Storek J, Wingard JR, Young JA, Boeckh MJ, Center for International Blood and Marrow Research; National Marrow Donor program; European Blood and Marrow Transplant Group (2009) American Society of Blood and Marrow Transplantation; Canadian Blood and Marrow Transplant Group; Infectious Diseases Society of America; Society for Healthcare Epidemiology of America; Association of Medical Microbiology and Infectious Disease Canada; Centers for Disease Control and Prevention. Guidelines for preventing infectious complications among hematopoietic cell transplantation recipients: a global perspective. Biol Blood Marrow Transplant 15(10):1143-238. https://doi.org/10.1016/j.bbmt.2009. 06.019

10. Edgar JDM, Richter AG, Huissoon AP, Kumararatne DS, Baxendale HE, Bethune CA, Garcez T, Misbah SA, Sorensen RU, United Kingdom Primary Immunodeficiency Network (UKPIN) Immunoglobulin Decision to Treat Study Group (2018)
Prescribing immunoglobulin replacement therapy for patients with non-classical and secondary antibody deficiency: an analysis of the practice of clinical immunologists in the UK and Republic of Ireland. J ClinImmunol 38(2):204-213. https://doi.org/10.1007/ s10875-017-0469-4

11. Ullmann AJ, Schmidt-Hieber M, Bertz H, Heinz WJ, Kiehl M, Krüger W, Mousset S, Neuburger S, Neumann S, Penack O, Silling G, Vehreschild JJ, Einsele Maschmeyer HG (2016) Infectious Diseases Working Party of the German Society for Hematology and Medical Oncology (AGIHO/DGHO) and the DAG-KBT (German Working Group for Blood and Marrow Transplantation). Infectious diseases in allogeneic haematopoietic stem cell transplantation: prevention and prophylaxis strategy guidelines 2016. Ann Hematol 95(9):1435-55. https://doi.org/10.1007/ s00277-016-2711-1

12. Raanani P, Gafter-Gvili A, Paul M, Ben-Bassat I, Leibovici L, Shpilberg O (2008) Immunoglobulin prophylaxis in hematological malignancies and hematopoietic stem cell transplantation. Cochrane Database Syst Rev 8(4):CD006501. https://doi.org/ 10.1002/14651858.CD006501.pub2

13. Jagasia MH, Greinix HT, Arora M, Williams KM, Wolff D, Cowen EW, Palmer J, Weisdorf D, Treister NS, Cheng GS, Kerr H, Stratton P, Duarte RF, McDonald GB, Inamoto Y, Vigorito A, Arai S, Datiles MB, Jacobsohn D, Heller T, Kitko CL, Mitchell SA, Martin PJ, Shulman H, Wu RS, Cutler CS, Vogelsang GB, Lee SJ, Pavletic SZ, Flowers ME (2015) National Institutes of Health Consensus Development Project on Criteria for Clinical Trials in Chronic Graft-versus-Host Disease: I. The 2014 Diagnosis and Staging Working Group report. Biol Blood Marrow Transplant 21(3):389-401.e1. https://doi.org/10.1016/j. bbmt.2014.12.001

14. Harris AC, Young R, Devine S, Hogan WJ, Ayuk F, Bunworasate U, Chanswangphuwana C, Efebera YA, Holler E, Litzow M, Ordemann R, Qayed M, Renteria AS, Reshef R, Wölfl M, Chen YB, Goldstein S, Jagasia M, Locatelli F, Mielke S, Porter D, Schechter T, Shekhovtsova Z, Ferrara JL, Levine JE (2016) International, multicenter standardization of acute graft-versus-host disease clinical data collection: a report from the Mount Sinai Acute GVHD International Consortium. Biol Blood Marrow Transplant 22(1):4-10. https://doi.org/10.1016/j.bbmt.2015.09.001

15. Glucksberg H, Storb R, Fefer A, Buckner CD, Neiman PE, Clift RA, Lerner KG, Thomas ED (1974) Clinical manifestations of graft-versus-host disease in human recipients of marrow from HLA-matched sibling donors. Transplantation 18(4):295-304. https://doi.org/10.1097/00007890-197410000-00001

16. Cordonnier C, Einarsdottir S, Cesaro S, Di Blasi R, Mikulska M, Rieger C, de Lavallade H, Gallo G, Lehrnbecher T, Engelhard D, Ljungman $\mathrm{P}$, on behalf of the European Conference on Infections in Leukaemia group (2019) Vaccination of haemopoietic stem cell transplant recipients: guidelines of the 2017 European Conference on Infections in Leukaemia (ECIL 7). The Lancet Infect Dis 19(6):E200-E212. https://doi.org/10.1016/S1473-3099(18) 30600-5

17. Common Terminology Criteria for Adverse Events (CTCAE) Version 5.0 e-pub: https://ctep.cancer.gov. Accessed 27 Nov 2017

18. Arai Y, Yamashita K, Mizugishi K, Kondo T, Kitano T, Hishizawa M, Kadowaki N, Takaori-Kondo A (2014) Risk factors for hypogammaglobulinemia after allo-SCT. Bone Marrow Transplant 49:859-861. https://doi.org/10.1038/bmt.2014.28

19. Frangoul H, Min E, Wang W, Chandrasekhar R, Calder C, Evans M, Manes B, Bruce K, Brown V, Ho R, Domm J (2013) Incidence and risk factors for hypogammaglobulinemia in pediatric patients following allo-SCT. Bone Marrow Transplant 48:1456-1459. https://doi.org/10.1038/bmt.2013.76

20. De Angelis F, Tosti ME, Capria S, Russo E, D'Elia GM, Annechini G, Stefanizzi C, Foà R, Pulsoni A (2015) Risk of secondary 
hypogammaglobulinaemia after Rituximab and Fludarabine in indolent non-Hodgkin lymphomas: A retrospective cohort study. Leuk Res 39(12):1382-1388. https://doi.org/10.1016/j.leukres. 2015.10.013

21. Forcina A, Rancoita PMV, Marcatti M, Greco R, Lupo-Stanghellini MT, Carrabba M, Marasco V, Di Serio C, Bernardi M, Peccatori J, Corti C, Bondanza A, Ciceri F (2017) A new clinicobiological scoring, system for the prediction of infection-related mortality and survival after allogeneic hematopoietic stem cell transplantation. Biol Blood Marrow Transplant 23(12):2151-2158. https:// doi.org/10.1016/j.bbmt.2017.08.010

22. Patel SY, Carbone J, Jolles S (2019) The expanding field of secondary antibody deficiency: causes, diagnosis, and management. Front Immunol 8(10):33. https://doi.org/10.3389/fimmu.2019. 00033

23. Perez EE, Orange JS, Bonilla F, Chinen J, Chinn IK, Dorsey M, El-Gamal Y, Harville TO, Hossny E, Mazer B, Nelson R, Secord E, Jordan SC, Stiehm ER, Vo AA, Ballow M (2017) Update on the use of immunoglobulin in human disease: a review of evidence. $\mathrm{J}$ Allergy ClinImmunol 139(3S):S1-S46. https://doi.org/10.1016/j. jaci.2016.09.023

24. Orange JS, Hossny EM, Weiler CR, Ballow M, Berger M, Bonilla FA, Buckley R, Chinen J, El-Gamal Y, Mazer BD, Nelson RP Jr, Patel DD, Secord E, Sorensen RU, Wasserman RL, CunninghamRundles C (2006) Primary Immunodeficiency Committee of the American Academy of Allergy, Asthma and Immunology. Use of intravenous immunoglobulin in human disease: a review of evidence by members of the Primary Immunodeficiency Committee of the American Academy of Allergy, Asthma and Immunology. J Allergy ClinImmunol 117(4 Suppl):S525-53. https://doi.org/10. 1016/j.jaci.2006.01.015

25. Ueda M, Berger M, Gale RP, Lazarus HM (2018) Immunoglobulin therapy in hematologic neoplasms and after hematopoietic cell transplantation. Blood Rev 32(2):106-115. https://doi.org/ 10.1016/j.blre.2017.09.003

26. Eichhorst B, Robak T, Montserrat E, Ghia P, Hillmen P, Hallek M, Mey U (2015) ESMO Guidelines Committee. Chronic lymphocytic leukaemia: ESMO clinical practice guidelines for diagnosis, treatment and follow-up. Ann Oncol 26(Suppl 5):v78-84. https:// doi.org/10.1093/annonc/mdv303

27. Jolles S, Chapel H, Litzman J (2017) When to initiate immunoglobulin replacement therapy (IGRT) in antibody deficiency: a practical approach. ClinExpImmunol 188(3):333-341. https://doi. org/10.1111/cei.12915

28. Cesaro S, Dalianis T, HanssenRinaldo C, Koskenvuo M, Pegoraro A, Einsele H, Cordonnier C, Hirsch HH. ECIL-6 Group (2018) ECIL guidelines for the prevention, diagnosis and treatment of BK polyomavirus-associated haemorrhagic cystitis in haematopoietic stem cell transplant recipients. J AntimicrobChemother 73(1):12-21. https://doi.org/10.1093/jac/dkx324
29. Sawinski D, Goral S (2015) BK virus infection: an update on diagnosis and treatment. Nephrol Dial Transplant 30(2):209-217. https://doi.org/10.1093/ndt/gfu023

30. Reis M, Ogonek J, Qesari M, Borges NM, Nicholson L, Preußner L, Dickinson AM, Wang XN, Weissinger EM, Richter A (2016) Recent developments in cellular immunotherapy for HSCT-associated complications. Front Immunol 14(7):500. https://doi.org/ 10.3389/fimmu.2016.00500

31. D'Costa S, Slobod KS, Benaim E, Bowman L, Cunningham J, Holladay M, Howlett N, Srivastava DK, Hurwitz JL (2001) Effect of extended immunosuppressive drug treatment on B cell vs $\mathrm{T}$ cell reconstitution in pediatric bone marrow transplant recipients. Bone Marrow Transplant 28(6):573-580. https://doi.org/10.1038/ sj.bmt. 1703185

32. Cordonnier C, Chevret S, Legrand M, Rafi H, Dhédin N, Lehmann B, Bassompierre F, Gluckman E. GREFIG Study Group (2003) Should immunoglobulin therapy be used in allogeneic stem-cell transplantation? A randomized, double-blind, dose effect, placebo-controlled, multicenter trial. Ann Intern Med 139(1):8-18. https://doi.org/10.7326/0003-4819-139-1-200307010-00007

33. Greinix HT, Pohlreich D, Kouba M, Körmöczi U, Lohmann I, Feldmann K, Zielinski C, Pickl WF (2008) Elevated numbers of immature/transitional CD21- B lymphocytes and deficiency of memory CD27+ B cells identify patients with active chronic graft-versus-host disease. Biol Blood Marrow Transplant 14(2):208-219. https://doi.org/10.1016/j.bbmt.2007.10.009

34. DeRienzo SY, Chiang KY, O'Neal WM, Godder K, Abhyankar S, Christiansen NP, Bridges KD, Henslee-Downey PJ (2000) Evaluation of the half-life of intravenous human cytomegalovirus immune globulin in patients receiving partially mismatched related donor bone marrow transplantation. Pharmacotherapy 20(10):1175-1178. https://doi.org/10.1592/phco.20.15.1175. 34592

35. Dimou M, Iliakis T, Maltezas D, Bitsani A, Kalyva S, Koudouna A, Kotsanti S, Petsa P, Papaioannou P, Kyrtsonis MC, Panayiotidis P (2018) Efficacy-safety of Facilitated Subcutaneous Immunoglobulin in Immunodeficiency Due to Hematological Malignancies. A Single-Center Retrospective Analysis Anticancer Res 38(7):4187-4191. https://doi.org/10.21873/anticanres.12712

36. Wasserman RL, Melamed I, Stein MR, Gupta S, Puck J, Engl H, Leibl W , McCoy B, Empson VG, Gelmont D, Schiff RI, IGSC, $10 \%$ with rHuPH20 Study Group (2012) Recombinant human hyaluronidase-facilitated subcutaneous infusion of human immunoglobulins for primary immunodeficiency. J Allergy ClinImmunol 130(4):951-7.e11. https://doi.org/10.1016/j.jaci.2012.06.021

Publisher's note Springer Nature remains neutral with regard to jurisdictional claims in published maps and institutional affiliations. 


\section{Authors and Affiliations}

\section{Ewa Karakulska-Prystupiuk ${ }^{1}$ [D - Jadwiga Dwilewicz-Trojaczek ${ }^{1}$. Joanna Drozd-Sokołowska ${ }^{1}$. Ewelina Kmin ${ }^{2}$. Marcin Chlebus ${ }^{3} \cdot$ Karolina Szczypińska $^{1}$ - Piotr Boguradzki ${ }^{1}$. Agnieszka Tomaszewska ${ }^{1} \cdot$ Krzysztof Mądry $^{1}$. Jarosław Biliński ${ }^{1}$. Grzegorz Władysław Basak ${ }^{1}$. Wiesław Wiktor Jędrzejczak ${ }^{1}$}

Jadwiga Dwilewicz-Trojaczek

jadwiga.dwilewicz-trojaczek@wum.edu.pl

Joanna Drozd-Sokołowska

johna.dr@poczta.fm

Karolina Szczypińska

karolina.szczypinska@uckwum.pl

Piotr Boguradzki

piotr.boguradzki@wum.edu.pl

Agnieszka Tomaszewska

agnieszka_tomaszewska@onet.eu

Krzysztof Mądry

kmadry@wum.edu.pl

Jarosław Biliński

jaroslaw.bilinski@gmail.com

Grzegorz Władysław Basak grzegorz.basak@wum.edu.pl
Ewelina Kmin

ewelina.kmin@uckwum.pl

Marcin Chlebus

mchlebus@wne.uw.edu.pl

Wiesław Wiktor Jędrzejczak

wieslaw.jedrzejczak@wum.edu.pl

1 Department of Hematology, Transplantation and Internal Medicine, Medical University of Warsaw, Banacha Str 1a, 02-097 Warsaw, Poland

2 Central Laboratory of the Medical University of Warsaw, Warsaw, Poland

3 Division of Quantitative Finance, Faculty of Economic Sciences, University of Warsaw, Warsaw, Poland 